\title{
Onsite Tests and Numerical Simulation of Broken Rock Zones in Surrounding Rocks of Seepage Roadways under Blasting
}

\author{
Zhouyuan Ye, Kun Pan, and Zhihua Zhou \\ School of Energy and Safety Engineering, Hunan University of Science and Technology, Xiangtan 411201, China \\ Correspondence should be addressed to Zhihua Zhou; zhouzhihua17@126.com
}

Received 18 September 2020; Revised 26 November 2020; Accepted 5 December 2020; Published 22 December 2020

Academic Editor: Hang Lin

Copyright (C) 2020 Zhouyuan Ye et al. This is an open access article distributed under the Creative Commons Attribution License, which permits unrestricted use, distribution, and reproduction in any medium, provided the original work is properly cited.

\begin{abstract}
To study the influence of blasting vibration on the broken rock zone around a seepage roadway and provide guidance for design of the roadway support, the broken rock zones around rock of seepage roadways under production blasting vibration are determined by onsite tests in a mining area, Daye iron mine. During the testing process, it is found that blasting vibration causes internal cracks of surrounding rocks to initiate and develop, the fracture density increases, the acoustic wave velocity of rock mass decreases, and the broken rock zones expand. At the same time, through onsite observation, it is found that blasting vibration results in crack development and formation of a water pathway to lead to surface water into the ground. The mechanical response around rock of the seepage roadway under blasting vibration is simulated by the two-dimensional realistic fracture progress analysis calculation software $\left(\mathrm{RFPA}^{2 \mathrm{D}}\right)$. It is found that internal cracks of roadway surrounding rock initiate, propagate, and join up gradually, and the fracture range is expanding under the seepage water pressure, ground stress, and cyclic loads, and the broken rock zones also expand. The results from numerical simulation are consistent with the results of onsite tests. It is also found that the tensile stress appears around some cracks, leading to part of the cracks more likely to generate shear failure under the seepage water pressure during simulation.
\end{abstract}

\section{Introduction}

During deep mining, the surrounding rock has always high ground stress and high hydraulic pressure $[1,2]$. As the depth increases, the pressure of the confined water becomes larger. Mining and excavation activities can easily lead to the expansion of fractures or activation of faults, thus forming relatively concentrated seepage channels. When the roof, floor, or wall of a roadway suddenly is destroyed, high-pressure karst water will enter the roadway and cause serious water inrush disaster. Due to the disturbance of blasting operation, the damage of rock mass is aggravated, and the water inrush disaster has obvious characteristics of suddenness and unpredictability [3]. Therefore, it is significant to guide the mine support and prevention of mine water inrush by monitoring the broken zone of the surrounding rock in the roadways under blasting load [4-6].
Many previous researchers have provided qualitative descriptions about the broken zone of the surrounding rock. Jiang et al. proposed the theoretical method to predict the development around the rock plastic zone in soft rock tunnels and discussed the effect of the mechanical properties of soft rock on loosening pressure [7]. Han et al. measured the broken rock zone of the surrounding rock in Zhongyi tunnel [8]. Wang et al. investigated the excavation damaged zone around roadways during longwall mining in a coal mine and found that dynamic pressure and faults contribute to the expansion of excavation damaged zones [9]. Yang et al. proposed an analytical time-dependent viscoelastic model for the evolution of fractured zone in the surrounding rock mass based on sliding crack model and equivalent crack method and simulated excavation damage zone in the surrounding rock mass of circular tunnel under lining and hydrostatic condition by using $\mathrm{RFPA}^{2 \mathrm{D}}[10]$. The broken 


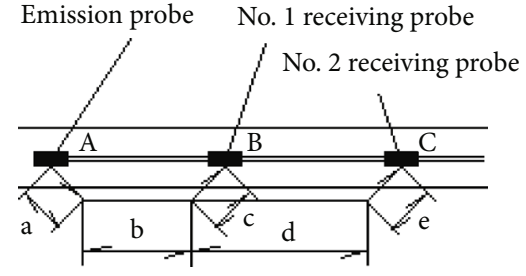

Figure 1: One transmitting double receiving refraction path diagram.

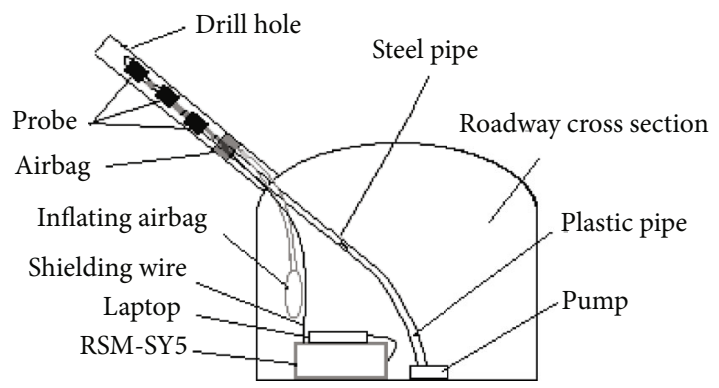

FIGURE 2: The diagram for testing the surrounding rock broken zone of an underground roadway.

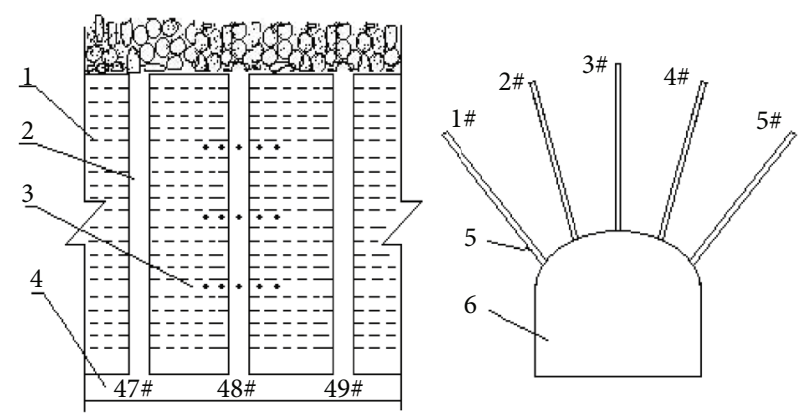

(1) projection plane of fan shaped blast hole

(2) stopping drift

(3) monitoring plane and hole position

(4) stopping contact taxiway

(5) drill hole

(6) roadway

Figure 3: Layout of measuring points and holes.

rock zones are affected by these factors, such as the ground stress, geological conditions, hydrostatic condition, and excavation methods. However, there are few papers about the combined effect of the ground stress, hydrostatic conditions, and blasting excavation.

For a proper investigation of the width of broken rock zones in the surrounding rock, in situ tests and computer simulations are needed. The tests of broken rock zones are conducted in the seepage roadway of one mining area in Daye iron mine, after blasting is carried out.

\section{Mining Area Condition}

The highest elevation in the testing mining area is $+250 \mathrm{~m}$, and the sublevel caving method is used in the mining area. The ore body is the concealed one, and its hanging wall



(I) after tunnel excavation

(II) after the first production blasting

(III) after several times production blasting

FIGURE 4: Corresponding curve of wave velocity and hole's depth of one hole in row 3.

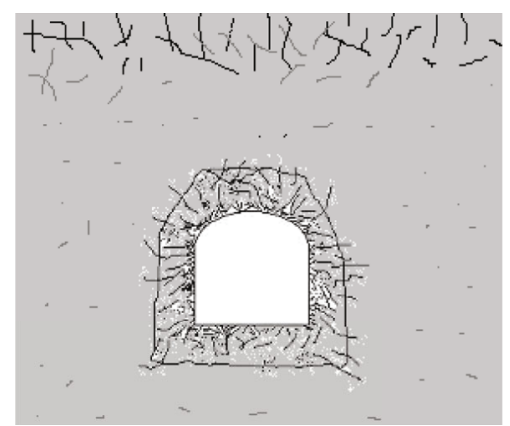

FIGURE 5: Crack distribution diagram of roadway surrounding rock.

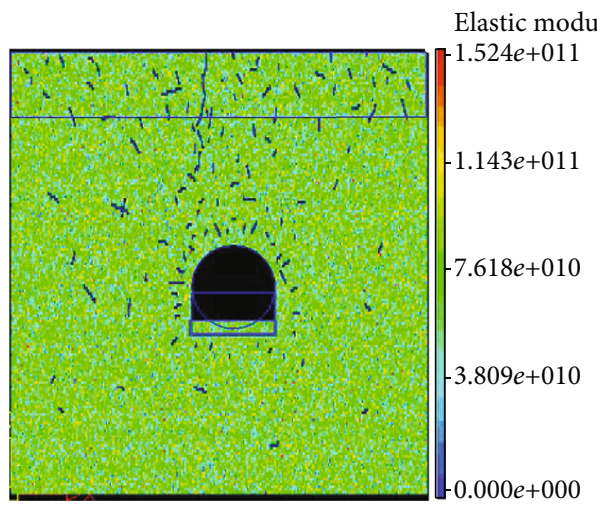

Figure 6: Calculation mode.

rock is metamorphic diorite. Part of the contacting zone between ore and rock is with frequent geological activity, rock crushing, which belongs to the unstable area type IV and V $[11,12]$. When constructing the roadway, the shotcrete-bolt support, partial the bolt-shotcrete-mesh support, is usually used, that can maintain the stability of the roadway tunnel. But during a segmented ore body is caving, the surrounding rock of the roadway is affected by the long-time and repeated production blasting vibration, seepage water pressure and ground pressure in the surrounding rock of the roadway will change, the roadway support will 
TABLE 1: Mechanical parameters of the calculation model for the seepage tunnel.

\begin{tabular}{|c|c|c|c|c|}
\hline $\begin{array}{l}\text { Homogeneous } \\
\text { degree }(\mathrm{m})\end{array}$ & $\begin{array}{l}\text { Average elastic } \\
\text { modulus }(\mathrm{MPa})\end{array}$ & Friction angle $\left({ }^{\circ}\right)$ & $\begin{array}{c}\text { Average compressive } \\
\text { strength }(\mathrm{MPa})\end{array}$ & Poisson ratio \\
\hline 3 & 90000 & 37 & 200 & 0.25 \\
\hline $\begin{array}{l}\text { Permeability } \\
\text { coefficient }\left(\mathrm{m} \mathrm{d}^{-1}\right)\end{array}$ & Porosity & $\begin{array}{l}\text { Pore pressure } \\
\text { coefficient }\end{array}$ & $\begin{array}{l}\text { Injury mutation } \\
\text { coefficient }\end{array}$ & $\begin{array}{l}\text { Coupling } \\
\text { coefficient }\end{array}$ \\
\hline $\begin{array}{l}\text { The upper } 1 \text {, } \\
\text { the lower } 0.001\end{array}$ & $\begin{array}{l}\text { The upper } 0.3 \text {, } \\
\text { the lower } 0.1\end{array}$ & 1 & 5 & 0.1 \\
\hline
\end{tabular}

gradually crack and deform, and some surrounding rocks will collapse, resulting in smashing rock drilling equipment, underground transportation will be blocked, especially part of the ore body cannot be recovered due to long roadway collapsing. In order to guide the roadway support and keep the roadway stable before blasting, it is necessary to test the broken zone of the surrounding rock in different periods in order to detect the gradual damage development of the surrounding rock.

\section{Onsite Determination of Surrounding Rock Broken Zone}

At present, there are many methods of measuring the surrounding rock broken zone. These methods can mainly be divided into two categories: electromagnetic wave detection and acoustic detection methods [13-17]. The acoustic detection method is to use the sound wave instrument and other equipment to excite sound (ultrasonic) waves through the rock into the receiving device, by analyzing the change of the acoustic parameters to determine the broken rock range. Because the equipment is simple and the price is relatively cheap, the sound wave method is used to detect the broken zone of the surrounding rock.

3.1. Test System. The RSM-SY5 intelligent acoustic test system is adopted through the refraction wave method in testing. The system is mainly composed of RSM-SY5 acoustic instrument, one emissive probe, two receiving probes (one transmitting double receiving form, as shown in Figure 1), a laptop, a pump, a pipe, wires, and a bracket.

As shown in Figure 2, single-hole refraction test steps are as follows:

(1) Sent the transceiver test probe to the hole test position with steel pipe and fix it with bracket

(2) Inflate the balloon below the hole probe by manual airbag, make it close to the hole wall, tighten the screws, and make the air the airtight gasbag to the bottom hole section form a closed space

(3) Pump water into the closed space, until it is full and the probe is completely submerged

(4) Keep the probe completely submerged state, and stimulate emission probe to test

(5) Select the appropriate stable waveform as a result of the test, record in the disk, and complete a test



FIGURE 7: Distribution of the seepage field in the surrounding rock of the seepage tunnel.

(6) Loosen the screw, discharged air out of the airtight bag, and retreat the rod back to the next measuring point position according to the test step distance, repeat the above process on to the next test

3.2. Measuring Point Placement. The measuring points are arranged in the $48^{\text {th }}$ extracting drift at the $-50 \mathrm{~m}$ level of the mining area, as shown in Figure 3. During the testing process, there is normal production of blasting and falling ore in the surrounding area nearby the measuring points, and the testing results can fully reflect the comprehensive effect of adjacent blasting. Three testing sections are arranged in the $48^{\text {th }}$ extracting drift, from caving ore blasting pile back to the roadway direction; every testing section consists of 5 testing holes in a row, adjacent testing sections are spaced 5 rows of blasting holes apart, and the row space of the blasting holes is $1.8 \mathrm{~m}$. The total length of the measuring area is about $28 \mathrm{~m}$. The testing holes are arranged in the roof of the $48^{\text {th }}$ extracting drift, and every hole is about $3 \mathrm{~m}$ depth and $50 \mathrm{~mm}$ in diameter. The layout is shown in Figure 3.

3.3. Test Results and Data Processing. The relationship between the velocity and hole depth is obtained from the data, as shown in Figure 4. It shows the relationship between the velocity and hole depth of No.1 hole of the $3^{\text {rd }}$ row. When the $48^{\text {th }}$ extracting drift formed, the surrounding broken rock zone is $1.28 \mathrm{~m}$, and the rock mass acoustic wave velocity is $4400 \sim 5400 \mathrm{~m} / \mathrm{s}$. After the No.1 row of blasting holes in the $48^{\text {th }}$ extracting drift blasted, the surrounding broken rock zone is $1.42 \mathrm{~m}$, and the rock mass acoustic wave velocity is $4000 \sim 4800 \mathrm{~m} / \mathrm{s}$. After several production blasting, the broken 


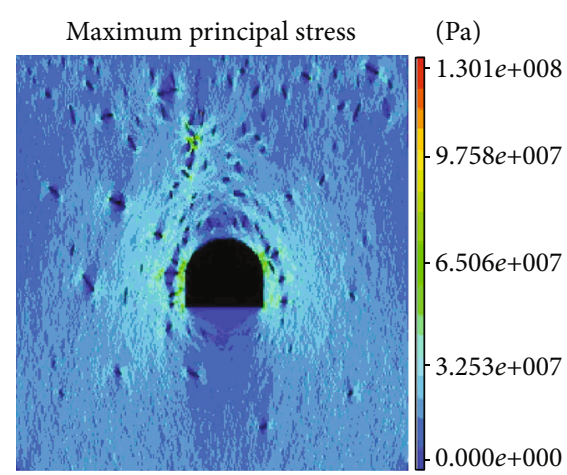

(a) Maximum principal stress

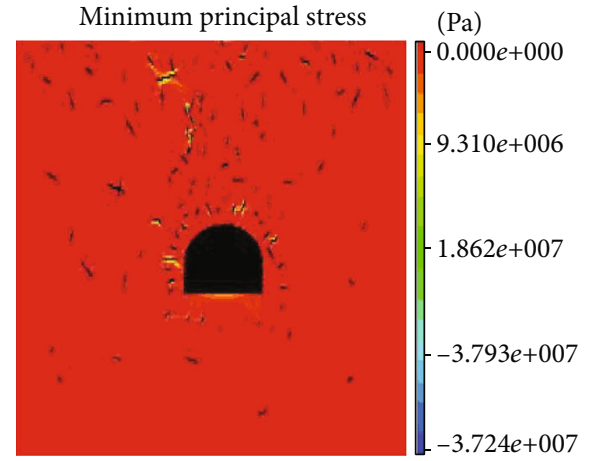

(b) Minimum principal stress

FIGURE 8: Stress distribution of roadway surrounding rock after excavation.



(a) At the peak time

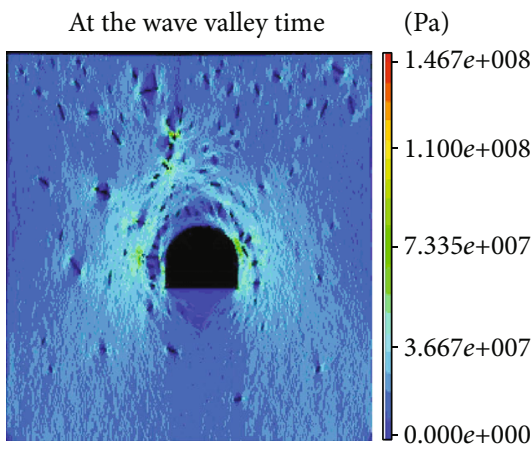

(b) At the wave valley time

FIGURE 9: Maximum principal stress evolution process in the first cycle.

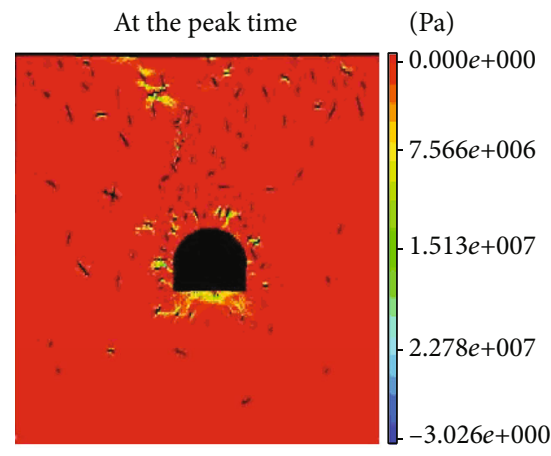

(a) At the peak time

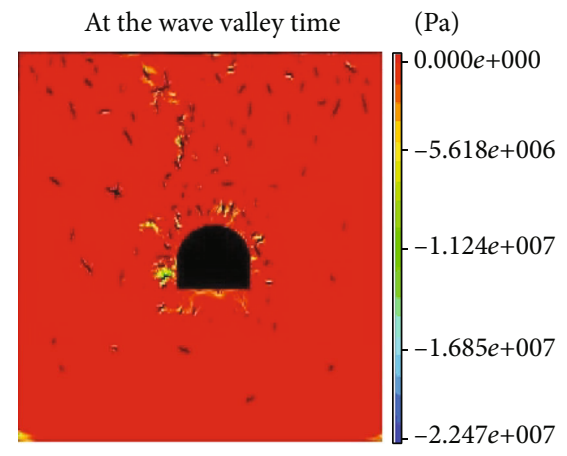

(b) At the wave valley time

FIgURE 10: Minimum principal stress evolution process in the first cycle.

rock zone is $1.50 \mathrm{~m}$, and the rock mass acoustic wave velocity is $1900 \sim 2500 \mathrm{~m} / \mathrm{s}$.

In the blasting vibration caused by rock crack initiation and propagation, the test wave velocity is reduced, and the repeated production blasting vibration makes crack continue to expand, its scope is increased, resulting in surrounding broken rock zones increased.

\section{Numerical Simulation of Seepage Damage}

The upper part of the rock mass is in the fissure zone nearby ground, and the roadway is in a wet state affected by the surface runoff. Due to the effect of blasting excavation, the surrounding rock of seepage roadway has more internal microcracks. The surrounding rock away from the roadway has good integrity, its internal fissure has less fracture compared with the upper zone and the surrounding broken rock zone, and it becomes a less penetrated layer, as shown in Figure 5.

4.1. Numerical Simulation Model. The seepage roadway section is U-shaped; the section is $3.4 \mathrm{~m}$ wide and $3 \mathrm{~m}$ high. According to the Saint Venant principle, the calculation model is determined as $17 \mathrm{~m}$ wide and $15 \mathrm{~m}$ high, and the roadway layout is in the middle. 


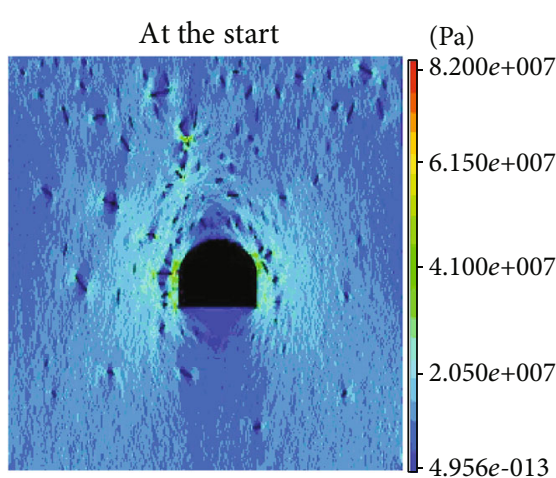

(a) At the start

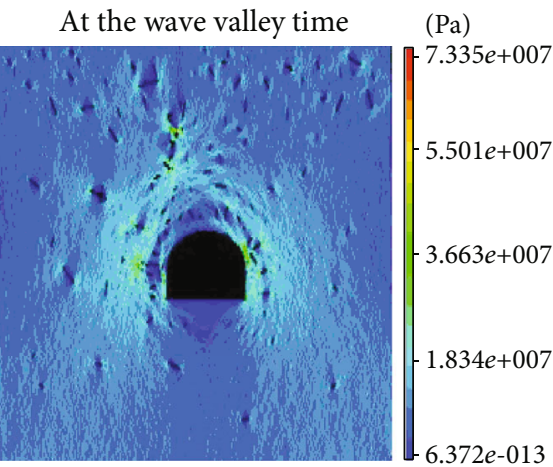

(c) At the wave valley time

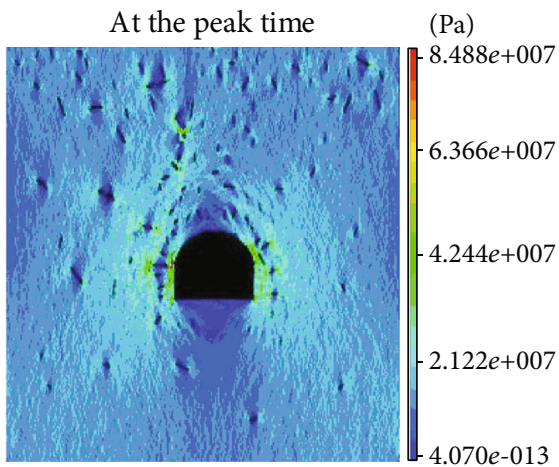

(b) At the peak time

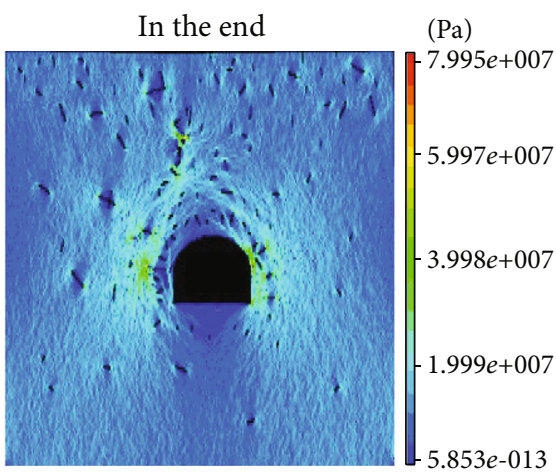

(d) In the end

Figure 11: Shear stress evolution process in the first cycle.

Considering the scene, there is only water dropping from the roadway walls before blasting mining; after a period of production blasting, there are two sites obviously changing with the weather: larger water flow when it rains and less when it is sunny. It is estimated that there is a crack through the earth surface. Using the RFPA2D-Flow system, the calculation model is established [18-21] as shown in Figure 6. According to the measured data and modeling experience [20-23], the mechanical parameters of the model are shown in Table 1.

The actual stress condition of the research part of the mining area is as follows: the vertical stress from the above is $7.47 \mathrm{MPa}$, the horizontal pressure is from $16 \mathrm{MPa}$ to 17.1 MPa from the top down and the periodical falling ore blasting vibration from the upper and horizontal direction. Therefore, the initial condition of the calculation model is set as follows: the vertical stress on the above surface is $7.47 \mathrm{MPa}$ and the horizontal pressure is from $16 \mathrm{MPa}$ to 17.1 MPa compliance with liner change. Upper boundary subjected to blasting vibration is assumed as the loading and unloading process, the loading process from the smallest stress to maximum stress is divided into four step, and the unloading process is divided into four steps too; the minimum is $0 \mathrm{MPa}$, and the maximum is $20 \mathrm{MPa}$; the inertia acceleration is $9.8 \mathrm{~m} / \mathrm{s}$, direction downward; the under surface constraints by displacement. The penetration pressure from the above is about $3 \mathrm{MPa}$.

4.2. The Seepage Field Evolution in Surrounding Rock of the Roadway. The seepage roadway elevation is $-50 \mathrm{~m}$, and the



FIGURE 12: Test diagram of the roadway surrounding broken rock zone.

surface vertical lever is $+250 \mathrm{~m}$ high, so the osmotic pressure head is $300 \mathrm{~m}$. When the production is not on, the water is infiltrated into the rock mass through the main crack and the branch cracks. So, the upper central has a large crack connected to the surface, and water through the crack penetrates into the rock. Because there is $300 \mathrm{~m}$ deep from the surface, the penetration pressure is about $3 \mathrm{MPa}$.

The internal fissure in the surrounding rock nearby the roadway is developed, and rock permeability is good and water in the fissure seeps down quickly into the roadway, so 
TABLE 2: Comparison between the measured and simulated results of broken rock zones in surrounding rock.

\begin{tabular}{lcccccccc}
\hline $\begin{array}{l}\text { Name } \\
\text { of holes }\end{array}$ & Measure $(\mathrm{m})$ & $\begin{array}{c}\text { First } \\
\text { Simulation }(\mathrm{m})\end{array}$ & Error $(\%)$ & Measure $(\mathrm{m})$ & $\begin{array}{c}\text { Second } \\
\text { Simulation }(\mathrm{m})\end{array}$ & Error $(\%)$ & $\begin{array}{c}\text { Third } \\
\text { Measure }(\mathrm{m})\end{array}$ & $\begin{array}{c}\text { Simulation }(\mathrm{m}) \\
\text { Error }(\%)\end{array}$ \\
\hline $1 \#$ & 1.28 & 1.14 & 10.9 & 1.42 & 1.26 & 11.3 & 1.50 & 1.27 \\
$2 \#$ & 1.51 & 1.26 & 16.6 & 1.54 & 1.41 & 8.4 & 1.63 & 1.46 \\
$3 \#$ & 1.51 & 1.49 & 1.3 & 1.54 & 1.50 & 2.6 & 1.71 & 1.53 \\
$4 \#$ & 1.48 & 1.25 & 15.5 & 1.56 & 1.34 & 14.1 & 1.61 & 1.35 \\
$5 \#$ & 1.37 & 1.18 & 13.9 & 1.54 & 1.26 & 18.2 & 1.70 & 1.37 \\
\hline
\end{tabular}

the water pressure in the surrounding rock nearby the roadway is almost zero.

Through simulation, it is clear to see the activation, extension progress that the main cracks in the upper part of the surrounding rock of the seepage roadway are in under the action of seepage pressure, ground stress, and cyclic loading. Cracks of the upper and lower surrounding rocks subjected to cyclic loading gradually expand and run through at a certain moment, as shown in Figure 7. The surface water pours into the roadway [24], which is consistent with the fact.

4.3. Stress Field Evolution in Surrounding Rock of Seepage Roadway. After the roadway excavation, surrounding rock is in equilibrium under the ground stress and seepage pressure, the maximum principal stress has a stress concentration phenomenon, and the minimum principal stress under the influence of seepage water pressure exists with local tension stress in some defects, as shown in Figure 8. The broken rock zones can be interpreted from the stress distribution. There is a stress-reducing area nearby the surface of the roadway, as shown in Figure 8(a), and the area within the outer boundary of the stress reduction zone is regarded as a broken rock zone.

The cyclic loading is loaded to simulate the vibration load produced by the blasting production. Under cyclic loading, the stress distribution in the first cycle is shown in Figures 9-11. At the starting point of cyclic loading, the maximum principal stress concentrates in the local area, as shown in Figure 8(a). As the stress increases to the peak of cyclic load, the maximum principal stress increases, the stress concentration becomes more obvious, and the stress at the concentration area also increases, as shown in Figure 9(a). Then, the cycle load gradually drops to the wave valley, the maximum principal stress decreases, and damages appear in the stress concentration area and part of stress release, as shown in Figure 9(b). After the cycle of load up to the end of the cycle, the maximum principal stress increases, the left surrounding rock of the roadway is damaged, and the stress concentration area transfers to the internal area of surrounding rock of the roadway.

During the course of the first cycle, the minimum principal stress decreases with cycle load increasing, and the number of the areas in which the tensile stresses exist has a tendency to increase, as shown in Figures 8(b) and 10(a). Under the effect of seepage water pressure, tensile stress appears around some cracks, which leads to some cracks more easily generating shear failure. The minimum principal stress reaches the minimum value at the wave valley of cycle loads, and the number of the areas in which the tensile stresses exist decreases, as shown in Figure 10(b).

The evolution of shear stress is similar to that of the maximum principal stress, as shown in Figure 11. It can be seen that the surrounding rock of roadways is damaged under repeated cyclic loading, and stress concentration area gradually transferred to the deep surrounding rock.

4.4. Extension Evolution of Broken Rock Zones of Seepage Roadways. The surrounding rock damage occurs under the action of hydraulic pressure, ground stress, and cyclic loadings, and the stress concentration area will transfer to the deep surrounding rock. According to the phenomenon of stress concentration area transferring, the damage state of the surrounding rock can be surveyed and the broken rock zones of surrounding rock can be determined. When the surrounding rock is subjected to the cyclic loading in the ground stress field and the seepage field, the new cracks in the surrounding rock will generate, the local stress will be released, and the concentrated stress area gradually transferred to the deep rock. Therefore, the lower stress area of roadway surrounding rock is the damaged area $[25,26]$. There is almost no development of the broken zone at the bottom of the roadway, but on the left side and the upper of the roadway, the broken zone is gradually enlarged, because of the main fracture zone, as shown in Figure 11.

According to the onsite measured hole position, measured holes are arranged on the simulate section, as shown in Figure 12. Measuring the lower stress area of the roadway surrounding rock, the broken rock zone is taken on the hole's direction. Similarly, measuring the stress distribution section of first three cycles, the broken rock zone is taken, as shown in Table 2 .

The simulation value of the broken rock zones of the roadway surrounding rock is smaller than the measured value, the maximum error is $19.4 \%$, and most of the error is within the allowable range. It shows that the results of the numerical simulation are consistent with that of the test.

\section{Conclusions}

(1) Through testing the broken rock zone of surrounding rock in the water seepage roadway of Daye iron mine mining area, it is found that blasting load makes the broken zone gradually expand; the test data obtained can provide the basis for roadway support design 
(2) Through the numerical simulation on surrounding broken rock zones in the seepage roadway, it is found that the cracks in the surrounding rock gradually initiate, expand, and run through under the effect of seepage pressure, ground stress, and cyclic loading, and the broken scope is enlarged. Under the effect of seepage water pressure, tensile stress appears around some cracks, which leads to the partial cracks more likely to generate shear failure. In the numerical simulation, with repeated cyclic load, part of the surrounding rock is damaged, the stress concentration area gradually transferred to the deep rock, and the range of surrounding broken rock zone of the roadway increases

\section{Data Availability}

The data in this article is raw data.

\section{Conflicts of Interest}

The authors declare that they have no conflicts of interest.

\section{Acknowledgments}

The support provided by the National Natural Science Foundation of China (Grant Nos. 51204068, 51404309), Key Laboratory of Anhui Province on Mining Response, Research Foundation of Education Bureau of Hunan Province, China (Grant No. 20A180 ), and Disaster Prevention in Deep Coal Mine (Grant No. KLDCMERDPC15102) is gratefully acknowledged.

\section{References}

[1] X. Li, J. Yao, and F. Gong, "Dynamic problems in deep exploitation of hard rock metal mines," The Chinese Journal of Nonferrous Metals, vol. 21, no. 10, pp. 2551-2563, 2011.

[2] Y. L. Zhao, L. Y. Zhang, J. Liao, W. J. Wang, Q. Liu, and L. Tang, "Experimental study of fracture toughness and subcritical crack growth of three rocks under different environments," International Journal of Geomechanics, vol. 20, no. 8, article 04020128, 2020.

[3] C. A. I. Lujun, P. E. N. G. Sheng, M. A. Jianjun, J. Bing, and Z. Xingcai, "Research on the stability of Jianlinshan stope in Daye iron mine," Construction \& Design for Engineering, no. 2, pp. 41-43, 2015.

[4] Z. Ye, F. Zhao, and Z. Zhou, "Mechanical characteristics of unloading rock under coupled dynamic and static loads," Chinese Journal of Geotechnical Engineering, vol. 35, no. 3, pp. 454-459, 2013.

[5] Z.-H. Zhou, Z. Ye, and Y. Duan, "Numerical simulation of the broken zone in soft rock roads," China Mining Magzine, vol. 18, no. 10, pp. 97-99, 2009.

[6] H. Zhou, C. K. Qu, D. W. Hu et al., "In situ monitoring of tunnel deformation evolutions from auxiliary tunnel in deep mine," Engineering Geology, vol. 221, no. 4, pp. 10-15, 2017.

[7] Y. Jiang, H. Yoneda, and Y. Tanabashi, "Theoretical estimation of loosening pressure on tunnels in soft rocks," Tunnelling and Underground Space Technology, vol. 16, no. 2, pp. 99-105, 2001.
[8] G. Han, B. Meng, H. Jing, and J. Wu, "Field experimental study on the broken rock zone of surrounding rock and the rock borehole shear tests of the large deformation tunnel," Advances in Materials Science and Engineering, vol. 2019, Article ID 1753518, 9 pages, 2019.

[9] H. Wang, Y. Jiang, S. Xue et al., "Assessment of excavation damaged zone around roadways under dynamic pressure induced by an active mining process," International Journal of Rock Mechanics and Mining Sciences, vol. 77, pp. 265-277, 2015.

[10] H. Yang, D. Huang, X. Yang, and X. Zhou, “Analysis model for the excavation damage zone in surrounding rock mass of circular tunnel," Tunnelling and Underground Space Technology, vol. 35, pp. 78-88, 2013.

[11] C. Zou, Analysis of Surrounding Rock Stability and Control Technology for Underground Mining Roadway in Daye Iron Mine, China University of Geosciences, Wuhan, 2014.

[12] M. Xu, Z. Du, G. Yao, and Z. Liu, "Rockburst prediction of chengchao iron mine during deep mining," Chinese Journal of Rock Mechanics and Engineering, vol. 27, Supplement 1, pp. 2918-2921, 2008.

[13] Q. Meng, Y. Men, Y. Yang, and H. Shen, "Roadway surrounding rock loose circle supporting theory and testing technology," China Mine Engineering, vol. 39, no. 3, pp. 47-51, 2010.

[14] Y. Wu, J. Zhai, and P. Xie, "Measurement of loosing circle in surrounding rock of gateway based on technology of geological radar detection," Coal Science and Technology, vol. 41, no. 3, pp. 32-38, 2013.

[15] C. Wan, X. Li, and C. Ma, "Optimization of support technology for deep soft rock roadway based on field measurement of excavation damage zone," Mining and Metallurgical Engineering, vol. 32, no. 1, pp. 12-16, 2012.

[16] L. Guo, J.-C. Li, Z.-C. Zhang, and C. Shoujin, "Research on surrounding rock loose zone of tunnel under unsymmetrical loading with ground penetrating radar and its application," Chinese Journal of Rock Mechanics and Engineering, vol. 30, Supplement 1, pp. 3009-3015, 2011.

[17] X. U. Kun, W. A. N. G. Zhijie, M. E. M. G. Xianglei, and C. Sun, "Research on detection technology for deep tunnel surrounding rock loose circle and numerical simulation analysis," Rock and Soil Mechanics, vol. 34, Supplement 2, pp. 464470, 2013.

[18] M. Xiao, Y. Zhang, J. Chen, and T. Hua, "Numerical analysis of excavation damaged zone of underground caverns induced by excavation blasting," Rock and Soil Mechanics, vol. 31, no. 8, pp. 2613-2618, 2010.

[19] Y. Zhao, Y. Wang, W. Wang, L. Tang, Q. Liu, and G. Cheng, "Modeling of rheological fracture behavior of rock cracks subjected to hydraulic pressure and far field stresses," Theoretical and Applied Fracture Mechanics, vol. 101, pp. 59-66, 2019.

[20] Y. Zhao, L. Zhang, W. Wang, Q. Liu, L. Tang, and G. Cheng, "Experimental study on shear behavior and a revised shear strength model for infilled rock joints," International Journal of Geomechanics, vol. 20, no. 9, article 04020141, 2020.

[21] Y. L. Zhao, C. S. Zhang, Y. X. Wang, and H. Lin, "Shear-related roughness classification and strength model of natural rock joint based on fuzzy comprehensive evaluation," International Journal of Rock Mechanics and Mining Sciences, p. 104550, 2020.

[22] T. Xu, C. A. Tang, Z. Zhang, and Y. Zhang, "Theoretical experimental and numerical studies on deformation and failure of 
brittle rock in uniaxial compression," Journal of Northeastern University(Natural Science), vol. 24, no. 1, pp. 87-90, 2003.

[23] K. Peng, J. Zhou, Q. Zou, Y. Zhang, and G. Tan, "Deformation characteristics and failure modes of sandstones under discontinuous multi-level cyclic loads," Powder Technology, vol. 373, pp. 599-613, 2020.

[24] Z. Zhou, P. Cao, Z. Ye, Y. Zhao, and W. Wan, "Failure characteristics of prestress fractured rock under uniaxial cyclic loading and seepage water pressure," Journal of Mining \& Safety Engineering, vol. 31, no. 2, pp. 292-298, 2014.

[25] H. Lin, H. Yang, Y. Wang, Y. Zhao, and R. Cao, "Determination of the stress field and crack initiation angle of an open flaw tip under uniaxial compression," Theoretical and Applied Fracture Mechanics, vol. 104, article 102358, 2019.

[26] K. Peng, Z. Liu, Q. Zou, Q. Wu, and J. Zhou, "Mechanical property of granite from different buried depths under uniaxial compression and dynamic impact: an energy-based investigation," Powder Technology, vol. 362, pp. 729-744, 2020. 